\title{
PELATIHAN SINGKAT TENTANG PENGETAHUAN DAN KETERAMPILAN DALAM DETEKSI DINI PERKEMBANGAN ANAK BALITA
}

\author{
Husni, Asmawati \\ Politeknik Kesehatan Kementerian Kesehatan Bengkulu, Jurusan Keperawatan, \\ Jalan Indragiri Nomor 03 Padang Harapan Bengkulu \\ husniyus2012@gmail.com
}

\begin{abstract}
The incidence of child development deviation in Indonesia reached 13\%-18\%. About $16 \%$ of children under five years got neurodevelopmental and brain disorders from mild to severe. This study aimed to determine the effect of brief training by using PreScreening Questionnaire Development (KPSP) to improve the knowledge and skills of parents in detection of child development. This study was quasi experimental with prepost test only. The population in this study were the parents / guardians of children at kinder garten of Baitul Izzah and Al Hasanah Bengkulu City. Samples were parents who have never participated in training and at least high school education. Number of samples 56 (28 intervention and 28 control) taken with concecutive sampling techniques. Data collection were using questionnaire for knowledge and checklist for skills. Statistical test independent t-test at the $\alpha 5 \%$ (one tail). The results showed the average age was 33 years, the average income was 2.3 million per month, more mothers working and have higher education. There were the difference in knowledge after being given brief training of 27.5 ( $\mathrm{p}$ value $=0.000$ ) and the difference in ability between the intervention and control groups ( $\mathrm{p}$ value $=0.000$ ). Effectiveness of brief training to increase the knowledge of $35 \%$. factor affecting the mother's knowledge was the age (p 0.001; OR: 2.12). We concluded that parents are expected to apply the child development detection according to ability at home and it is needed training for other parents.
\end{abstract}

Keywords: Training, Knowledge, Development, Child

Abstrak: Angka kejadian deviasi perkembangan anak di Indonesia mencapai $13 \%-18 \%$.
Sekitar $16 \%$ anak dibawah usia lima tahun mengalami gangguan perkembangan saraf
dan otak mulai ringan hingga berat. Tujuan penelitian adalah untuk mengetahui pengaruh
pelatihan singkat penggunaan Kuisioner Pra Screening Perkembangan (KPSP) terhadap
peningkatan pengetahuan dan keterampilan orang tua dalam deteksi perkembangan anak.
Jenis penelitian quasi eksperimen dengan pre post test only. Populasi dalam penelitian ini
adalah orang tua / wali murid anak PAUD Baitul Izzah dan PAUD Al Hasanah Kota
Bengkulu. Sampel adalah orang tua balita yang belum pernah mengikuti pelatihan dan
pendidikan minimal SLTA. Jumlah sampel 56 orang ( 28 intervensi dan 28 kontrol)
diambil dengan teknik concecutive sampling. Pengumpulan data pengetahuan dengan
kuisioner dan data keterampilan menggunakan checklist. Uji statistik independent t-test
pada $\alpha 5 \%$ (one tail). Hasil penelitian menunjukkan usia rata-rata orang tua adalah 33
tahun, penghasilan rata-rata 2,3 juta perbulan, lebih banyak ibu bekerja, berpendidikan
tinggi. Ada perbedaan pengetahuan setelah diberikan pelatihan singkat sebesar 27.5 ( $p$
value $=0.000$ ) dan perbedaan kemampuan antara kelompok intervensi dan control (p
value=0.000). Efektifitas pelatihan singkat terhadap peningkatan pengetahuan sebesar 35
$\%$. Faktor yang mempengaruhi pengetahuan ibu adalah usia (p 0.001 ; OR : 2,12 ). Orang 
tua diharapkan menerapkan deteksi perkembangan anak sesuai kemampuan di rumah dan perlu dilakukan pelatihan bagi orang tua lainnya.

Kata Kunci: pelatihan, pengetahuan, perkembangan, anak

Perkembangan merupakan sebuah peningkatan skill dan kemampuan anak untuk berfungsi (perubahan secara kualitatif) (Pilittery, 2012) yang merupakan salah satu determinan kesehatan yang penting dalam rentang kehidupan tertentu. (Anderson, et al, 2010). Angka kejadian deviasi perkembangan pada anak di negara Amerika Serikat berkisar 12-16\%, Thailand 24\%, dan Argentina 22\% sedangkan di Indonesia berkisar antara 13\%-18\% (Hidayat, 2010). Menurut Ariani (2009), di Indonesia didapatkan sekitar $16 \%$ anak dibawah usia lima tahun mengalami gangguan perkembangan saraf dan otak mulai ringan hingga berat, dan setiap 2 dari 1000 bayi mengalami gangguan perkembangan motorik serta 1 dari 100 anak mempunyai kecerdasan kurang dan keterlambatan bicara. Pembinaan perkembangan secara komprehensif dan berkualitas diselenggarakan melalui kegiatan stimulasi, deteksi dan intervensi dini penyimpangan tumbuh kembang balita pada masa krisis tersebut. Test untuk penilaian/skrining perkembangan pada seorang anak yang sudah terbukti menunjukkan sensitivitas dan spesifisitas baik adalah menggunakan Denver II dan Kuisioner PreSkrining Perkembangan (KPSP). Perbedaannya adalah DDST II sampai saat ini hanya dapat digunakan pada profesi kesehatan (Depkes RI 2009).

Departemen Kesehatan RI justru mengharapkan pada tahun 2010, sebanyak $80 \%$ anak balita sudah dilakukan penilaian/skrining perkembangan agar dapat dilakukan intervensi dini terhadap anak yang dicurigai mengalami gangguan perkembangan (Depkes,2009). Deteksi dini tumbuh kembang yang bertujuan untuk identifikasi dini perkembangan anak usia 3 bulan sampai 6 tahun di tingkat pelayanan kesehatan dasar berupa KPSP yang bertujuan untuk mengetahui perkembangan seorang anak apakah sesuai dengan usianya ataukah ditemukan kecurigaan penyimpangan yang yang dapat dilakukan tenaga kesehatan, kader, guru PAUD serta orang tua. KPSP dapat mengidentifikasi berbagai aspek perkembangan, diantaranya gerakan kasar, sosialisasi dan kemandirian, bicara dan bahasa serta motorik halus (Depkes RI, 2009).

Penekanan pada orangtua (parent concern) akan pentingnya perkembangan anak merupakan modal utama dalam melakukan deteksi dini gangguan perkembangan. Orang tua dapat dikenalkan tahap pertumbuhan dan perkembangan dari bayi baru lahir hingga remaja yang dilalui melalui perencanaan asuhan keperawatan (Pilitteri, 2010). Penelitian yang dilakukan oleh Kadi, Garna \& Fadlyana (2008) menunjukkan bahwa metode KPSP merupakan salah satu alat skrining yang dapat dilakukan untuk menilai perkembangan anak. Penelitian terhadap 85 anak usia 12-14 bulan di Puskesmas Garuda Bandung dan Rumah Sakit Hasan Sadikin didapatkan 15 anak $(17,6 \%)$ mengalami gangguan perkembangan. Didukung penelitian Ariani dkk (2009) pada 60 anak anak usia 1-3 tahun didapatkan $26 \%$ mengalami perkembangan kurang baik menggunakan KPSP. Penelitian tentang deteksi dini perkembangan anak balita menggunakan KPSP di Kota Bengkulu belum peneliti temukan dari berbagai sumber.

Berdasarkan data hasil survei awal di beberapa sekolah taman kanak-kanak (TK) yang ada kota Bengkulu didapatkan bahwa banyak orang tua belum memiliki pengetahuan dan keterampilan tentang deteksi perkembangan anak serta belum pernah ada program pemberian informasi 
melalui pelatihan tentang deteksi gangguan perkembangan anak.

\section{BAHAN DAN CARA KERJA}

Penelitian ini merupakan quasi eksperimental, dengan pre dan post test only. Penelitian ini untuk mengukur rerata pengetahuan dan keterampilan orang tua tentang deteksi dini perkembangan anak melalui pemberian intervensi pelatihan singkat metode KPSP pada kelompok intervensi dan pemberian modul pada kelompok non intervensi. Populasi dalam penelitian ini adalah orang tua/wali murid anak balita di PAUD wilayah Kota Bengkulu. Kriteria sampel ibu yang belum pernah mengikuti pelatihan tumbuh kembang, bersedia mengikuti kegiatan pelatihan, pendidikan minimal SMP, anak sekolah di PAUD Kota Bengkulu. Penelitian dilaksnakan dari bulan Nopember-Desember 2014. Data pengetahuan diukur melalui pre and post test. Keterampilan tentang deteksi tumbuh kembang melalui format KPSP. Analisis dilakukan dengan uji $\mathrm{T}$ dan multivariate menggunakan regresi liner ganda.

\section{HASIL}

\section{Karakteristik Responden}

Responden dalam penelitian ini berjumlah 63 orang, karakteristik responden dapat digambarkan dalam tabel 1.

Tabel 1. menunjukkan bahwa umur, pendidikan pekerjaan dan penghasilan keluarga berdistribusi normal ( $\mathrm{p}$ value $>\alpha$ $=0,05)$.
Tabel 1. Gambaran karakteristik dan kesetaraan responden $(n=63)$

\begin{tabular}{|c|c|c|c|}
\hline \multirow[t]{2}{*}{ Variabel } & \multicolumn{2}{|c|}{ Kelompok } & \multirow{2}{*}{$\begin{array}{c}\mathbf{p} \\
\text { value }\end{array}$} \\
\hline & $\begin{array}{l}\text { Non } \\
\text { Intervensi } \\
(\mathbf{n}=\mathbf{2 9})\end{array}$ & $\begin{array}{l}\text { Intervensi } \\
(\mathrm{n}=34)\end{array}$ & \\
\hline $\begin{array}{l}\text { Umur, mean }(S D) \\
\text { Median } \\
\text { Min-maks } \\
\text { CI } 95 \%\end{array}$ & $\begin{array}{l}33(4,5) \\
32 \\
31-35 \\
31,6-35,2\end{array}$ & $\begin{array}{l}33(4,7) \\
33 \\
31-35 \\
31,4-34,7\end{array}$ & 0,758 \\
\hline $\begin{array}{l}\text { Penghasilan } \\
\text { mean (SD) } \\
\text { Median } \\
\text { Min-maks } \\
\text { CI } 95 \%\end{array}$ & $\begin{array}{l}2,3(1,2) \\
2,0 \\
1-7 \\
1,9-2,8\end{array}$ & $\begin{array}{l}2,3(0,72) \\
2,0 \\
1-7 \\
2,0-2,5\end{array}$ & 0,868 \\
\hline $\begin{array}{l}\text { Pekerjaan } \sum(\%) \\
\text { Bekerja } \\
\text { Tidak bekerja }\end{array}$ & $\begin{array}{l}17(51,5) \\
12(40)\end{array}$ & $\begin{array}{l}18(60) \\
16(48,5)\end{array}$ & 0,122 \\
\hline $\begin{array}{l}\text { Pendidikan } \sum(\%) \\
\text { SMA } \\
\text { PT }\end{array}$ & $\begin{array}{l}5(23,8) \\
26(59,1)\end{array}$ & $\begin{array}{l}16(76,2) \\
18(40,9)\end{array}$ & 0,08 \\
\hline
\end{tabular}

Efektifitas Intervensi Pelatihan Singkat terhadap Pengetahuan dan Keterampilan Orang Tua dalam Deteksi Perkembangan Anak Balita

Pengetahuan dan keterampilan responden tentang deteksi perkembangan anak dinilai setelah kegiatan pelatihan selesai pada hari kedua pelatihan untuk kelompok intervensi. Kelompok non intervensi pengetahuan dan keterampilan dinilai setelah 2-3 hari membaca modul pelatihan.

Tabel 2. menjelaskan bahwa terdapat perbedaan pengetahuan responden setelah diberikan intervensi sebesar 17,5 point. Intervensi pelatihan efektif dalam meningkatkan pengetahuan sebesar 35 $\%$. 
Tabel 2. Perbedaan Pengetahuan Dan Keterampilan Dalam Deteksi Perkembangan Sebelum Dan Sesudah Dilakukan Intervensi Di Kota Bengkulu Tahun $2014(\mathrm{~N}=63)$

\begin{tabular}{ccccccc}
\hline \multirow{2}{*}{ Variabel } & \multicolumn{5}{c}{ Pengetahuan dan Keterampilan Deteksi Perkembangan } \\
\cline { 2 - 6 } & $\begin{array}{c}\text { Sebelum } \\
\text { intevensi (A) } \\
\text { mean (SD) }\end{array}$ & $\begin{array}{c}\text { Sesudah } \\
\text { intervensi (B) } \\
\text { mean (SD) }\end{array}$ & $\begin{array}{c}\text { Selisih (B- } \\
\text { A) mean } \\
\text { (SD) }\end{array}$ & $\begin{array}{c}\text { Perubahan } \\
\text { dalam kelompok } \\
\text { (p value) }\end{array}$ & $\begin{array}{c}\text { Perubahan } \\
\text { antarkelompok } \\
\text { (p value) }\end{array}$ & $\begin{array}{c}\text { Efektifitas } \\
(\%)\end{array}$ \\
\hline $\begin{array}{c}\text { Pengetahuan } \\
\text { Non intervensi }\end{array}$ & $64,8(10,9)$ & $69,6(11,0)$ & $4,8(7,9)$ & $0,001 *$ & $0,000^{*}$ & $35,03 \%$ \\
$\quad$ Intervensi & $61,4(19,0)$ & $78,9(18,7)$ & $27,5(1,4)$ & & \\
Keterampilan & & $44,1(32,4)$ & & & $0.000^{*}$ \\
$\quad$ Non intervensi & & $88,7(12,2)$ & & & \\
Intervensi & & & & & \\
\hline
\end{tabular}

\section{Analisis Multivariat}

\section{Pengaruh Intervensi dan Karakteristik Responden terhadap Peningkatan Pengetahuan dan Keterampilan dalam Deteksi Perkembangan Anak Balita}

Karakteristik yang berhubungan
dengan pengetahuan dan orang tua dalam deteksi perkembangan balita dianalisis secara multivariat untuk mengidentifikasi adanya perubahan pengetahuan dan keterampilan orang tua setelah diberikan pelatihan singkat. Analisis regresi linear ganda dapat dijelaskan pada tabel 3.

Tabel 3. Karakteristik Responden yang Berkontribusi terhadap Pengetahuan Orang Tua dalam Deteksi Perkembangan Anak Balita

\begin{tabular}{lllllll}
\hline Karakteristik & $\mathbf{B}$ & SE & $\mathbf{B}$ & $\mathbf{P}$ & $\mathbf{r}$ & $\mathbf{R}^{\mathbf{2}}$ \\
\hline Intervensi dan control & 12.131 & 2.944 & 0.379 & 0.000 & 0.749 & 0,562 \\
Usia & -0.237 & 0.318 & -0.068 & 0.459 & & \\
Pendidikan & 1.870 & 3.382 & 0.055 & 0.582 & & \\
Penghasilan & 1.355 & 1.505 & 0.081 & 0.372 & & \\
Pengetahuan pra intervensi & 0.666 & 0.097 & 0.646 & 0.000 & & \\
\hline
\end{tabular}

Tabel 3 menunjukkan bahwa karakteristik responden memliliki hubungan $(\mathrm{r}=0,749)$ dengan pengetahuan orang tua tentang deteksi perkembangan anak balita sebesar $56,2 \%\left(\mathrm{R}^{2}=0,562\right)$. Variabel yang tidak memiliki pengaruh adalah variable tingkat usia, pendidikan dan penghasilan responden.

Dari analisis tabel 5 meunjukkan bahwa karakteristik responden memliliki hubungan $(r=0,763)$ dengan keterampilan orang tua dalam deteksi perkembangan anak balita sebesar $58 \%\left(\mathrm{R}^{2}=0,581\right)$. Variabel yang tidak memiliki pengaruh adalah pengetahuan post intervensi, pekerjaan, pendidikan dan penghasilan responden. sehingga variable tersebut harus dikeluarkan dari pemodelan multi variate. Hasil pemodel akhir yang dapat di lihat pada tabel 6 .

Tabel 6. Karakteristik Responden yang Paling Berkontribusi terhadap Keterampilan Orangtua dalam Deteksi Perkembangan Anak Balita

\begin{tabular}{|c|c|c|c|c|c|c|}
\hline Karakteristik & B & SE & B & $\mathbf{p}$ & $\mathbf{r}$ & $\mathbf{R}^{2}$ \\
\hline Constant & 114.836 & 20.434 & & $0.000 *$ & 0.748 & 0.559 \\
\hline Intervensi dan control & 43.856 & 5.490 & 0.674 & $0.000 *$ & & \\
\hline Usia ibu & -2.122 & 0.601 & $\begin{array}{l}-0.298 \\
\end{array}$ & $0.001 *$ & & \\
\hline
\end{tabular}




\section{Pengaruh Karakteristik terhadap Pengetahuan dan Keterampilan Responden tentang Deteksi Perkembangan Anak Menggunakan KPSP}

Hasil penelitian menunjukkan bahwa karakteristik responden memliliki hubungan dengan pengetahuan dan keterampilan orang tua tentang deteksi perkembangan anak balita. Hasil uji regresi didapatkan bahwa kelompok yang diberikan pelatihan singkat tentang deteksi perkembangan menggunakan Kuisioner Praskrining Perkembagan (KPSP) lebih tinggi skor pengetahuan tentang deteksi perkembangan balita sebesar 11,724 point setelah dikontrol variable pengetahuan awal yang dimiliki dan keterampilan tentang deteksi perkembangan balita sebesar 43,856 point setelah dikontrol usia.

Depkes (1993) menentukan komponen yang dapat berpengaruh terhadap keberhasilan pelatihan antara lain : kurikulum, pengajar/pelatih, penyelenggara, sarana yang digunakan, metode serta karakteristik peserta pelatihan seperti umur, pekerjaan, pendidikan, dan pengalaman. Faktor-faktor yang dapat mempengaruhi tingkat pengetahuan adalah pendidikan, umur, pengalaman, status sosial, ekonomi, budaya dan kondisi kesehatan (Notoatmodjo, 2005). Semakin tinggi tingkat pendidikan seseorang maka semakin tinggi pula tingkat pengetahuannya, semakin bertambah umur seseorang maka pengetahuannya akan semakin bertambah, pengalaman seseorang akan menambah wacana dan meningkatkan pengetahuannya, semakin tingi status sosial, ekonomi, budaya dan kondisi kesehatan seseorang maka semakin tinggi pula tingkat pengetahuannya.

$\begin{array}{lcr}\text { Efektifitas } & \text { Pelatihan } & \text { terhadap } \\ \text { Peningkatan } & \text { Pengetahuan } & \text { dan } \\ \text { Keterampilan } & \text { Responden } & \text { tentang } \\ \text { Deteksi } \quad \text { Perkembangan } & \text { Anak } \\ \text { Menggunakan KPSP } & \end{array}$

Hasil penelitian didapatkan bahwa terjadi peningkatan pengetahuan tentang deteksi tumbuh kembang balita pada kelompok intervensi maupun kelompok non intervensi. Peningkatan skor pengetahuan lebih banyak terjadi pada kelompok intervensi dengan rerata peningkatan sebesar 27,5. Efektifitas pelatihan singkat dapat meningkatkan pengetahuan dan keterampilan orang tua sebesar $35 \%$.

Hasil penelitian di atas sejalan dengan pendapat Notoatmodjo (2005), pelatihan memiliki tujuan penting untuk meningkatkan pengetahuan dan keterampilan sebagai kriteria keberhasilan program kesehatan secara keseluruhan. Depkes (2008) menyatakan bahwa tujuan pelatihan merupakan upaya peningkatan sumberdaya manusia termasuk sumberdaya manusia tenaga kesehatan, kader posyandu, agar pengetahuan dan keterampilannya meningkat.

Senada dengan hasil penelitian Suharmini dkk tentang pelatihan karakteristik dan deteksi tumbuh kembang anak usia dini bagi kader posyandu plus didapatkan hasil bahwa para kader yang mengikuti pelatihan menyatakan bertambahnya pemahaman mengenai karakteristik tumbuh kembang anak dan keterampilan mendeteksi secara dini disfungsi tumbuh kembang anak. (Kadi.2008).

Hasil penelitian juga sejalan dengan hasil penelitian Aulianingtias dan Kurniawan tentang penelitian pelatihan keterampilan pengasuhan dapat meningkatkan pemahaman orang tua tentang anak ditemukan ada perubahan pemahaman orangtua mengenai cara mengasuh anak. Perubahan pemahaman ini diikuti pula dengan perubahan perilaku orangtua mengasuh anak. Namun, hanya 
empat dari tujuh responden yang mengakui adanya perubahan ini.

\section{KESIMPULAN}

Ada peningkatan rata-rata

Pengetahuan dan keterampilan orang tua

\section{DAFTAR RUJUKAN}

Anderson, L.W \& David R.K. 2010. Kerangka

Landasan untuk Pembelajaran,

Pengajaran, dan Asesmen Yogyakarta : Pustaka Pelajar.

Ariani, dkk. 2012. Usia Anak dan Pendidikan Ibu sebagai Faktor Risiko Gangguan Perkembangan Anak. Jurnal Kedokteran Brawijaya, Vol. 27, No. 2.

Aulianingtias dan Kurniawan. Pelatihan keterampilan pengasuhan dapat meningkatkan pemahaman orang tua tentang anak. (www.naskah-publikasi diakses 28 September 2014)

Depkes, RI. 2009. Pedoman Pelatihan stimulasi, Deteksi dan Intervensi Dini Tumbuh Kembang Anak di Tingkat Pelayanan Kesehatan dasar.

Dhamayanti. Meita. 2006. Kuisioner Praskrining Perkembangan (KPSP) Anak. Jurnal Sari Pediatri, vol 8, no.1: 9-15.

Hidayat. 2010. Optimalisasi Penggunaan KPSP pada Keluarga sebagai Upaya Pencegahan Gangguan Perkembangan Anak. www.kpsp.klg diakses 1 Oktober 2014. setelah dilakukan intervensi. Faktor yang mempengaruhi pengetahuan responden adalah pengetahuan yang dimiliki sebelumnya. Pelatihan singkat efektif meningkatkan pengetahuan dan keterampilan orang Tua sebesar $35 \%$.

IDAI. 2002. Ilmu Kesehatan Anak. Jakarta . FKUI Kadi, Garna \& Fadlyana, 2008. Kesetaraan Hasil Skrining Risiko Penyimpangan Perkembangan Menurut Cara KPSP dan Denver II pada Anak Usia 12-14 Bulan dengan Berat Lahir Rendah, Sari Pediatri, vol 10 no. 1

Notoatmodjo. 2005. Pendidikan dan Perilaku Kesehatan. Jakarta: Rineka Cipta.

Pilitteri. 2012. Maternal and Child Health Nursing, edisi 6. Philadelpia: Lippincot William Wilkins.

Soetjiningsih. 2005. Tumbuh Kembang Anak. EGC. Jakarta.

Suharmini, dkk. 2009. Pelatihan Karakteristik dan Deteksi Tumbuh Kembang Anak Usia Dini bagi Kader Posyandu Plus. Jurnal Inovasi dan Aplikasi Teknologi, vol 13, no.1.

Sukesi, dkk. 2014. Manajemen Penatalaksanaan Deteksi Dini Tumbuh Kembang Anak di Posyandu Kelurahan Manyaran. website.diakses 28 September 2014

Sukiarko, 2007. Pengaruh Pelatihan dengan Metode BBM (Belajar Berdasarkan Masalah). Tesis. Tidak Dipublikasikan. 